\title{
GOMMENTARY
}

\section{Mandating Clinician COVID-19 Vaccination May Hinder Population-Level Uptake}

Aimee R. Eden, PhD, MPH; Anastasia J. Coutinho, MD, MHS

(Fam Med. 2021;53(6):404-7.)

doi: 10.22454/FamMed.2021.545121

$\mathbf{H}$ ealth care worker vaccine hesitancy has great impact not only on a worker's individual health, but on the health of their patients, patient families, and on a population level. Because voluntary uptake of many vaccines, including the novel SARS coronavirus 2 (COVID-19) mRNA vaccine, has not been sufficient, vaccine mandates for health care workers have been suggested as one mechanism to ensure patient and health worker safety. ${ }^{1,2}$ In the current pandemic climate, the question arises: should clinicians, especially those who provide direct patient care, be mandated to get the COVID-19 vaccine? We argue that despite legal precedent for requiring vaccines, setting mandates for COVID-19 vaccines for health care professionals would be detrimental to population-level uptake, a high level of which is necessary to curb the pandemic. ${ }^{3}$

Legal precedent for mandatory vaccinations dates from Jacobson $v$ Massachusetts (1905) when the US Supreme Court declared that vaccine mandates were a reasonable requirement to protect public health, public safety, and the common good. This decision challenged the valuing of individual liberty over the common good, ${ }^{4}$ a tension that continues to impede a strong federal response to many issues in public health. Yet, more than a century later, this remains the benchmark case for state power to mandate vaccination, a power which has not gone unchallenged..$^{5,6}$ Given the global socioeconomic impact of the COVID-19 pandemic, there is, then, legal precedent for mandated COVID-19 vaccination, especially in health care settings. However, the three COVID-19 vaccines currently authorized for use by the FDA have not yet been fully licensed but are approved under an Emergency Use Authorization (EUA). Because an EUA does not require the same level of safety and efficacy data as full FDA approval, mandating vaccines with an EUA may not currently be legally (or ethically) justifiable and may compromise public trust. ${ }^{3}$ After COVID-19 vaccines have full Biologics License Application (BLA) approval, mandates may be considered by states and/or healthcare facilities.?

Ethical implications of mandating vaccinations have been robustly debated. ${ }^{5-10}$ Health care workers have an ethical responsibility to protect the health of patients and populations, as do the institutions in which they work. ${ }^{11}$ The American Medical Association (AMA) Code of Medical Ethics describes the physician's ethical obligation to protect patients and to do no harm, in part by preventing the spread of disease in their practice settings. ${ }^{12}$ Further, it can be argued that health care workers are morally obliged to set a good example of disease prevention for the public, including building trust in the safety and efficacy of vaccines. ${ }^{3,9,10}$ Voluntary acceptance of vaccination would fulfill these obligations. Fortunately, most physicians have high COVID-19 vaccination uptake without mandates ${ }^{13}$ but notably, physicians have been more accepting of the vaccine than other health care workers, including nurses and medical assistants. ${ }^{14,15}$

From the American Board of Family Medicine, Lexington, KY (Dr Eden); and La Clinica de la Raza, Concord, CA (Dr Coutinho). 
Influenza, a virus often compared to COVID-19, can also lead to hospitalization and death, yet voluntary uptake by health care workers has not achieved the CDC's $90 \%$ goal. ${ }^{2}$ As a result, some states have enacted mandates for health care workers; 18 states currently have laws that require influenza vaccination of hospital health care workers, and 11 states require vaccination of ambulatory care facility health care workers. ${ }^{16,17}$ Despite the laws' existence, not all enforce demonstration of health worker vaccination or impose consequences for those who abstain..$^{10}$ Institutions with influenza vaccine mandates that included consequences for nonadherence resulted in higher rates of vaccine uptake than those without, and institutions in states with health care worker vaccine laws were more likely to implement mandates with consequences. ${ }^{18}$ An increasing number of facilities, even in states without formal statutes, are requiring their health care workers, as a condition of employment, be vaccinated against influenza unless medically contraindicated, a move which has significantly increased vaccination rates among health workers. ${ }^{19,20}$

Beyond legal and ethical considerations of health workers and their employers, the tension between mandated health worker vaccination and individual choice has been healthily deliberated in the context of other diseases. Mandates have been shown to increase health care worker vaccine uptake, ${ }^{19,20}$ thus protecting health care workers, staff, and patients from the spread of infections, including COVID-19. Increased uptake also reduces illness and absenteeism, ${ }^{16,21}$ which can be especially impactful during a crisis. However, mandates can be considered coercive and counter to the deeply embedded cultural and political values of individual choice. A study of health care workers at one institution found that the most frequently reported reason for refusal of the influenza vaccine was a perceived violation of freedom of choice and personal autonomy, and these workers looked unfavorably on vaccine mandates. ${ }^{23}$ The burdens already carried by health workers caring for COVID-19 patients is another reason that forcing them to receive the vaccine may not be warranted. ${ }^{3}$ Upholding individual free will by protecting the right to vaccination choice can have indirect positive effects, while mandating health care workers to be vaccinated may ultimately undermine trust, ${ }^{3,10}$ reinforce public antivaccination sentiment, ${ }^{9}$ and inhibit population-level vaccination efforts. ${ }^{3,24}$
While mandates may work in certain sociocultural contexts, ${ }^{22}$ in the United States, mandates should be applied with caution. Because mandates can be perceived as antithetical to cultural values of individual freedoms, implementing mandates, even for targeted segments of the population, may unintentionally backfire, like some states' attempts to mandate social distancing and mask wearing. Mandating the COVID-19 vaccine for health care workers may also exacerbate community mistrust; vaccine-hesitant patients may imply a forced nature of vaccination to even those freely choosing to be vaccinated. Scientific and political populism may even lead to weaponization of the mandates by antivaccination groups. ${ }^{25}$

Given the historical and ongoing systematized and structural racism in medicine, ${ }^{26-28}$ equity and justice must be part of vaccine mandate decisions. Medical racism, combined with the fraught political context under which the COVID-19 vaccines were developed and authorized, ${ }^{29}$ has led some Black physicians and health workers to express COVID-19 vaccine hesitancy, especially during the early clinical trials. ${ }^{30}$ Though overall disparities in COVID-19 infection, hospitalization, and mortality rates in the United States extend to Black health care workers, who are more likely to die from COVID than White workers ${ }^{31}$ a recent US study found that Black and Hispanic health care workers had lower vaccine acceptance than Asian or White workers..$^{14}$ This may have downstream implications for population uptake, since African-American individuals have significantly higher levels of trust in vaccine advice from race-concordant medical authority figures than discordant. ${ }^{32,3} 3$ Furthermore, the National Medical Association (NMA), a professional society promoting the collective interests of physicians and patients of African descent, conducted their own review of the vaccine trial results before ultimately endorsing the emergency use of the COVID-19 vaccine, ${ }^{30,34}$ but the organization has not issued a statement in support of health care worker vaccine mandates.

The most effective vaccine policies to achieve herd immunity during a global pandemic will take into consideration a nuanced analysis of the political and cultural context in which these policies are implemented. Indeed, as an analysis of various European vaccination programs has demonstrated, vaccine policies both reflect and reproduce historically and culturally shaped state-society relationships. ${ }^{22}$ Further, vaccination policies can have both mandatory 
and voluntary elements, ${ }^{22}$ and policies based on arguments that follow a simplistic binary distinction will fail to have the desired effects. For now, we suggest that the implication of COVID-19 vaccine mandates for health care workers should be carefully considered. Vaccine mandates will serve to protect patients and staff only in communities where uptake among health care workers is low. Given the current divisive political environment in the United States, increasingly overt culture wars, historical and ongoing medical racism, and misinformation and antiscience sentiment spreading in unprecedented ways, vaccination mandates, especially at a governmental level, may backfire and should be used judiciously.

CORRESPONDING AUTHOR: Address correspondence to Dr Aimee R. Eden, American Board of Family Medicine, 1648 McGrathiana Pkwy, Ste 550, Lexington, KY 40511. 859-269-5626. aeden@theabfm.org.

\section{References}

1. Daniel W, Nivet M, Warner J, Podolsky DK. Early evidence of the effect of SARS-CoV-2 vaccine at one medical center. N Engl J Med. 2021:NEJMc2102153; Epub ahead of print. doi:10.1056/NEJMc2102153

2. Stewart AM. Using state laws to vaccinate the healthcare workforce. Public Health Rep. 2012;127(2):224-227. doi:10.1177/003335491212700212

3. Gostin LO, Salmon DA. The dual epidemics of COVID-19 and influenza: vaccine acceptance, coverage, and mandates. JAMA. 2020;324(4):335-336. doi:10.1001/jama.2020.10802

4. Gostin LO. Jacobson v Massachusetts at 100 years: police power and civil liberties in tension. Am J Public Health. 2005;95(4):576-581. doi:10.2105/AJPH.2004.055152

5. Ottenberg AL, Wu JT, Poland GA, Jacobson RM, Koenig BA, Tilburt JC. Vaccinating health care workers against influenza: the ethical and legal rationale for a mandate. Am J Public Health. 2011;101(2):212-216. doi:10.2105/AJPH.2009.190751

6. Stewart AM. Mandatory vaccination of health care workers. N Engl J Med. 2009;361(21):2015-2017. doi:10.1056/ NEJMp0910151

7. Gostin LO, Salmon DA, Larson HJ. Mandating COVID-19 vaccines. JAMA. 2021;325(6):532-533. doi:10.1001/ jama.2020.26553

8. El Amin AN, Parra MT, Kim-Farley R, Fielding JE. Ethical issues concerning vaccination requirements. Public Health Rev. 2012;34(1):14. doi:10.1007/BF03391666

9. Van Hooste WLC, Bekaert M. To be or not to be vaccinated? The ethical aspects of Influenza vaccination among healthcare workers. Int J Environ Res Public Health. 2019;16(20):3981. doi:10.3390/ijerph16203981

10. Dubov A, Phung C. Nudges or mandates? The ethics of mandatory flu vaccination. Vaccine. 2015;33(22):2530-2535. doi:10.1016/j.vaccine.2015.03.048
11. Cortes-Penfield N. Mandatory influenza vaccination for health care workers as the new standard of care: a matter of patient safety and nonmaleficent practice. Am J Public Health. 2014;104(11):2060-2065. doi:10.2105/ АJPH.2013.301514

12. AMA amends ethical guidance on physician immunizations [press release]. Chicago: American Medical Association; November 16, 2020. https://www.ama-assn.org/press-center/ press-releases/ama-amends-ethical-guidance-physicianimmunizations. Accessed April 14, 2021.

13. Dror AA, Eisenbach N, Taiber S, et al. Vaccine hesitancy: the next challenge in the fight against COVID-19. Eur J Epidemiol. 2020;35(8):775-779. doi:10.1007/s10654-020-00671-y

14. Shekhar R, Sheikh AB, Upadhyay S, et al. COVID-19 vaccine acceptance among health care workers in the United States. Vaccines (Basel). 2021;9(2):119. doi:10.3390/vaccines9020119

15. Bernard R. Physicians highly accepting of COVID-19 vaccine. Medical Economics. February 9, 2021. https://www. medicaleconomics.com/view/physicians-highly-accepting-ofcovid-19-vaccine. Accessed Feb 28, 2021.

16. Menu of State Hospital Influenza Vaccination Laws (cdc. gov). Atlanta, GA: Centers for Disease Control and Prevention. https://www.cdc.gov/phlp/docs/menu-shfluvacclaws.pdf. Accessed March 15, 2021.

17. Menu of State Ambulatory Care Facility Influenza Vaccination Laws. Atlanta, GA: Centers for Disease Control and Prevention. https://www.cdc.gov/phlp/publications/topic/ menus/acfinfluenza/index.html. Accessed March 15, 2021.

18. Nowalk MP, Lin CJ, Raymund M, Bialor J, Zimmerman RK. Impact of hospital policies on health care workers' influenza vaccination rates. Am J Infect Control. 2013;41(8):697-701. doi:10.1016/j.ajic.2012.11.011

19. Babcock HM, Gemeinhart N, Jones M, Dunagan WC, Woeltje KF. Mandatory influenza vaccination of health care workers: translating policy to practice. Clin Infect Dis. 2010;50(4):459464. doi:10.1086/650752

20. Rakita RM, Hagar BA, Crome P, Lammert JK. Mandatory influenza vaccination of healthcare workers: a 5-year study. Infect Control Hosp Epidemiol. 2010;31(9):881-888. doi:10.1086/656210

21. Frederick J, Brown AC, Cummings DA, et al. Protecting healthcare personnel in outpatient settings: the influence of mandatory versus non-mandatory influenza vaccination policies on workplace absenteeism during multiple respiratory virus seasons. Infect Control Hosp Epidemiol. 2018;39(4):452461. doi:10.1017/ice.2018.9

22. Paul KT, Loer K. Contemporary vaccination policy in the European Union: tensions and dilemmas. J Public Health Policy. 2019;40(2):166-179. doi:10.1057/s41271-019-00163-8

23. Hakim H, Gaur AH, McCullers JA. Motivating factors for high rates of influenza vaccination among healthcare workers. Vaccine. 2011;29(35):5963-5969. doi:10.1016/j.vaccine.2011.06.041

24. Verger P, Dubé E. Restoring confidence in vaccines in the COVID-19 era. Expert Rev Vaccines. 2020;19(11):991-993. doi:10.1080/14760584.2020.1825945

25. Gostin LO. Mandatory HPV vaccination and political debate. JAMA. 2011;306(15):1699-1700. doi:10.1001/jama.2011.1525

26. Katz RV, Warren RC, eds. The search for the legacy of the USPHS syphilis study at Tuskegee. Lanham, MD: Lexington Books; 2011. 
27. Gravlee CC. Systemic racism, chronic health inequities, and COVID-19: A syndemic in the making? Am J Hum Biol. 2020;32(5):e23482. doi:10.1002/ajhb.23482

28. Yearby R. Reifying racism in the COVID-19 pandemic response. Am J Bioeth. 2021;21(3):75-78. doi:10.1080/1526516 1.2020.1870773

29. Egede LE, Walker RJ. Structural racism, social risk factors, and Covid-19: a dangerous convergence for Black Americans. N Engl J Med. 2020;383(12):e77. doi:10.1056/ NEJMp2023616

30. Boodman E. Not trusting the FDA, Black doctors' group creates panel to vet Covid-19 vaccines. STAT. Published September 21, 2020. https://www.statnews.com/2020/09/21/ black-doctors-group-creates-panel-to-vet-covid19-vaccines/. Accessed Feb 18, 2021.

31. Anyane-Yeboa A, Sato T, Sakuraba A. Racial disparities in COVID-19 deaths reveal harsh truths about structural inequality in America. J Intern Med. 2020;288(4):479-480. doi:10.1111/joim.13117
32. Fu LY, Haimowitz R, Thompson D. Community members trusted by African American parents for vaccine advice. Hum Vaccin Immunother. 2019;15(7-8):1715-1722. doi:10.1080/21 645515.2019.1581553

33. Langer Research Associates. COVID collaborative survey: coronavirus vaccination hesitancy in the Black and Latinx communities. COVID Collaborative. Published November 23, 2020. https://www.covidcollaborative.us/content/vaccinetreatments/coronavirus-vaccine-hesitancy-in-black-andlatinx-communities. Accessed March 29, 2021.

34. Advisory Statement on Federal Drug Administration's Emergency Use Authorization Approval for Pfizer and Moderna Vaccine. Silver Spring, MD: National Medical Association; December 21, 2020. https://www.nmanet.org/ news/544970/NMA-COVID-19-Task-Force-on-Vaccines-andTherapeutics.htm. Accessed March 28, 2021. 